\title{
Una filosofía humanista de la educación
}

jpanedas@lasallep.edu.mx

Jesús Ignacio Panedas Galindo*

Martín López Calva

Trillas, 2006

Martín López es una persona con una larga experiencia en el campo de la enseñanza, y en concreto, en la impartición y reflexión de materias relacionadas con las humanidades. En este ejemplar presentamos la segunda edición de su tesis doctoral.

Su preocupación fundamental a lo largo de todo el trabajo es ofrecer guías con la finalidad de construir una educación "personalizante". En medio del bombardeo mediático de los actuales centros educativos que prometen educación en valores y de manera personalizada, nuestro autor centra todas su atención en destacar en la educación lo que desde siempre le ha pertenecido, su carácter personalizante. Su objetivo esencial es: "hacer una seria investigación reflexiva para tratar de descubrir algunos fundamentos o exigencias básicas para reorientar cualquier programa o acción de formación de profesores, para después tratar de actualizar en el terreno específico de la escuela o de la universidad, procesos TRANSformativos genuinos que contribuyan a la construcción histórica de educación personalizante".

No se conforma en reducir la educación a la labor de transmisión de conocimientos, como si lo único importante fuera la capacitación. Tampoco le parece suficiente el embarnizamiento de la escuela con bonitas palabras que incluyan valores, axiología y otras estrategias mercadológicas.

La educación es el proceso en el que de manera acompañada se trabaja por encontrar el camino particular de cada persona. En ese caminar no solamente se fijan en los conocimientos, o en los sentimientos, sino también en la experiencia de vida.

Para establecer los cambios necesarios en la educación el autor presta atención a la figura del maestro como piedra fundamental. La TRANS-formación del maestro tiene dos valores esenciales: en primer lugar, es la manera de que esta figura no caduque por el ímpetu de las nuevas tecnologías de comunicación; en segundo, se constituye en la parte central del proceso modificador de la educación.

El autor clave que acompaña el periplo de Martín López es el jesuita Bernard Lonergan. Aclara 
el autor del libro que no es el objetivo de su escrito hacer un estudio detallado sobre una o varias de las obras o ideas de Lonergan. Es su marco teórico más consultado, pero no se trata de hacer un ensayo sobre él. La protagonista sigue siendo la educación personalizante.

El libro tiene 4 grandes partes. En la primera de ellas, se ocupa del método trascendental que el autor toma y hace suyo de Lonergan. Se fija también en la pluralidad y riqueza que posee y es el sujeto humano. Se le contempla de manera dinámica y observando cuáles son los procesos según los cuales cada quién decide y se adapta a lo que considera valioso.

En la parte II, se ocupa de los distintos tipos de inteligencia y de la relación de ésta con los sentimientos. También considera importante la labor que se haga en el proceso educativo con los sentimientos. Éstos también son educables. Es más, van a ser los que en muchos casos reales de la vida nos ayuden a decidirnos sobre lo que más nos conviene. En este apartado dialoga directamente con Goleman y Gardner como representantes destacados en la investigación sentimental.

La parte III se centra en los procesos concretos que se tendrían que cuidar para ofrecer una formación adecuada de los maestros en la línea de una educación personalizada. La TRANS-formación interna del profesor redunda en su mejor desempeño y en la TRANS-formación del hecho educativo.

En la cuarta y última parte, integra lo más arriba dicho con la situación mundial en lo que respecta a la educación. Aquí se detiene en la estructura dinámica de actualización cooperativa magisterial en sus tres niveles:

a. desarrollo de la noción de TRANS-formación docente como bien particular:

b. el segundo nivel explora la TRANS-formación docente compartiendo con cooperativa. otros colegas interesados para progresar juntos y de manera distin-

c. por último, el tercer nivel, sondea las aportaciones necesarias que los enrillamado tos actores del proceso pedagógico pueden aportar con la finalidad de quecer y completar la construcción teórica del campo disciplinario educación.

Me parece que quedan suficientemente destacados los puntos fuertes de este grueso volumen. Me parece, a modo de sugerencia, que el tema del análisis real y contextual del alumno contemporáneo es también piedra clave para renovar el proceso educativo. El maestro no puede hacer todo si no sabe rigurosamente con quién tiene que estar trabajando. La labor educativa es un esfuerzo en el que la participación de las distintas partes es imprescindible.

Algo más también pudiera decirse de los padres de familia y de la situación actual de las relaciones familiares. 